\title{
Gremlin gene expression in bovine retinal pericytes exposed to elevated glucose
}

\author{
R Kane, L Stevenson, C Godson, A W Stitt, C O'Brien
}

Br J Ophthalmol 2005;89:1638-1642. doi: 10.1136/bjo.2005.069591

See end of article for authors' affiliations

Correspondence to:

Professor Colm O'Brien Institute of Ophthalmology, 60 Eccles Street, Dublin 7, Ireland; cobrien@mater.ie

Accepted for publication 10 July 2005

\begin{abstract}
Aim: To assess the influence of high extracellular glucose on the expression of the bone morphogenetic protein (BMP) antagonist, gremlin, in cultured bovine retinal pericytes (BRPC).

Methods: BRPC were cultured under conditions of $5 \mathrm{mM}$ and $30 \mathrm{mM}$ D-glucose for 7 days and total RNA was isolated. Gremlin mRNA levels were correlated, by RT-PCR, with other genes implicated in the pathogenesis of diabetic retinopathy and the signalling pathways in high glucose induced gremlin expression were probed using physiological inhibitors. Gremlin expression was also examined in the retina of streptozotocin induced diabetic mice.

Results: High glucose stimulated a striking increase in BRPC gremlin mRNA levels in parallel with increases in mRNA for the growth factors vascular endothelial growth factor (VEGF), transforming growth factor $\beta$ (TGF $\beta$ ), and connective tissue growth factor (CTGF) and changes in other genes including fibronectin and plasminogen activator inhibitor-1 (PAl-1). High glucose triggered gremlin expression was modulated by anti-TGF $\beta$ antibody, by the uncoupler of oxidative phosphorylation, CCCP, and by inhibition of MAPkinase (MAPK) activation. Striking gremlin expression was observed in the outer retina of diabetic mice and also at the level of the vascular wall.

Conclusions: Gremlin gene expression is induced in BRPC in response to elevated glucose and in the retina of the streptozotocin induced diabetic mouse. Its expression is modulated by hyperglycaemic induction of the MAPK, reactive oxygen species, and TGF $\beta$ pathways, all of which are reported to have a role in diabetic fibrotic disease. This implicates a role for gremlin in the pathogenesis of diabetic retinopathy.
\end{abstract}

$\mathrm{D}$ abetic retinopathy is one of the most frequent causes of new blindness in the working age population. ${ }^{1}$ There is a strong and consistent relation between hyperglycaemia and the incidence and progression of diabetic retinopathy. Clinical studies have reported that the normalisation of glycaemia control can prevent diabetic microangiopathies and possibly cardiovascular complications. ${ }^{2}$ Several mechanisms exist by which hyperglycaemia results in retinal damage, including increased polyol pathway, activation of protein kinase C (PKC), increased nonenzymatic glycation, ${ }^{6}$ and generation of reactive oxygen species (ROS) by oxidative stress. ${ }^{7}$ Furthermore, other mediators, including growth factors such as vascular endothelial growth factor (VEGF), platelet derived growth factor (PDGF), and transforming growth factor $\beta$ (TGF $\beta$ ) contribute to the pathological manifestations of diabetic retinopathy, including basement membrane thickening, vessel occlusion and retinal hypoxia, which induces neovascularisation (reviewed by Cai and Boulton ${ }^{8}$ ). New vessels and connective tissue grow on the surface of the retina or optic nerve head and into the vitreous. Visual loss at this time results from vitreous haemorrhage or fluid exudation from fragile new vessels. ${ }^{9}$

Retinal pericytes are smooth muscle-like cells with attenuated processes enveloping the abluminal surface of microvessels and sharing a common basement membrane with the underlying endothelium (reviewed by Diaz-Flores et $\left.a l^{10}\right)$. Pericytes express $\alpha$ smooth muscle actin ( $\alpha$-SMA) and have been implicated to have a contractile function, ${ }^{11}$ thus regulating blood flow. They are proposed to regulate microvascular angiogenesis and synthesise components of the vascular basement membrane. ${ }^{12}{ }^{13}$ Pericytes have been demonstrated to be involved in the regulation of endothelial cell number and morphology and microvessel architecture. ${ }^{14}$
One of the first histological features of diabetic retinopathy is the loss of retinal pericytes. ${ }^{15}$

Gremlin is a member of the differential screening-selected gene aberrative in the neuroblastoma (DAN) family of bone morphogenetic protein (BMP) antagonists. ${ }^{16}$ The protein is highly conserved through evolution and contains a cysteine rich region, a cysteine knot, which is also shared by members of the TGF $\beta$ family, PDGF family, nerve growth factor, and other secreted proteins. ${ }^{17}$ Gremlin exists as both secreted and cell associated forms. It can be post-translationally modified by glycosylation and phosphorylation..$^{18}$ Gremlin influences diverse processes in growth, differentiation, and development ${ }^{19} 20$

Gremlin has been demonstrated to antagonise the activities of BMP-2, BMP-4, and BMP-7. It does this by direct binding to and heterodimerisation with the BMP. This then results in these BMP ligands failing to bind their receptors, which are members of the TGF $\beta$ receptor superfamily. ${ }^{16}{ }^{19}$ Increased expression of gremlin has recently been demonstrated in several models of diabetic nephropathy, ${ }^{21}{ }^{22}$ pointing to a role for gremlin in diabetic fibrotic disease. In this study, we explore gremlin expression in a model of diabetic eye disease, using BRPC cultured in high glucose levels. We also examine in vivo gremlin expression in the retina of C57 mice with streptozotocin induced diabetes.

\footnotetext{
Abbreviations: $\alpha$-SMA, $\alpha$ smooth muscle actin; BMP, bone morphogenetic protein; BRPC, bovine retinal pericytes; CCCP, carbonyl cyanide $m$-chlorophenylhydrazone; CTGF, connective tissue growth factor; DAN, differential screening-selected gene aberrative in the neuroblastoma; EST, expressed sequence tag; MAPK, MAP-kinase; PAI1 , plasminogen activator inhibitor-1; PDGF, platelet derived growth factor; PKC, protein kinase C; ROS, reactive oxygen species; RT-PCR, reverse transcription-polymerase chain reaction; TGF $\beta$, transforming growth factor $\beta$; VEGF, vascular endothelial growth factor
} 


\section{METHODS}

\section{Cell culture}

Bovine retinal pericytes (BRPC) were cultured in MCDB 131 (Invitrogen) supplemented with $2 \mathrm{mM}$ L-glutamine and $5 \%$ fetal bovine serum (passages 5-7), and maintained in medium containing either $5 \mathrm{mM}$ or $30 \mathrm{mM}$ D-glucose for 7 days. Culture medium was replenished three times during this period to maintain glucose levels in the desired range. For the low/high glucose experiments $(\mathrm{n}=3)$ BRPC were cultured in $5 \mathrm{mM}$ glucose, $30 \mathrm{mM}$ glucose, or $5 \mathrm{mM}$ glucose and $25 \mathrm{mM}$ mannitol (as an osmolarity control) for 7 days. To examine regulation of gremlin expression BRPC were cultured in $30 \mathrm{mM}$ glucose plus $10 \mu \mathrm{M}$ PD 98059 (Calbiochem), or $10 \mu \mathrm{M}$ GF 109203X (Calbiochem), or $500 \mathrm{nM}$ CCCP (Sigma), or $1 \mu \mathrm{g} / \mathrm{ml}$ $\alpha$ TGF $\beta 1$ antibody (R\&D Systems) for 7 days. PD 98059 is a selective inhibitor of $\mathrm{MEK}^{23}$ that acts by inhibiting activation of MAPK and subsequent phosphorylation of MAK substrates. GF $109203 X$ is a selective PKC inhibitor. ${ }^{24}$ CCCP (carbonyl cyanide $m$-chlorophenylhydrazone) is an uncoupler of oxidative phosphorylation. ${ }^{25}$ सTGF $\beta 1$ antibody neutralises the bioactivity of TGF $\beta 1 .{ }^{26}$ BRPC were also cultured in $5 \mathrm{mM}$ glucose with $10 \mathrm{ng} /$ $\mathrm{ml}$ TGF $\beta 1$ or $10 \mathrm{ng} / \mathrm{ml}$ TGF $\beta 2$.

\section{RNA extraction and reverse transcription-polymerase chain reaction}

RNA was extracted from BRPC using Trizol (Invitrogen) according to the manufacturers' instructions. RT-PCR (reverse transcription-polymerase chain reaction) was performed as follows: $2 \mu \mathrm{g}$ of total RNA was treated with DNaseI (Invitrogen), reverse transcription was carried out using random primers and Superscript II (Invitrogen) using the manufacturer's protocol. Limited cycle PCR was carried out using the following primers: VEGF; sense 5'-GGA TCA AAC CTC ACC AAA GC-3', antisense 5'-CAG GAT TGT TCT GTC GAT GG-3', CTGF, sense 5'-GAA AGG CAA AAA GTG CAT CC-3', antisense 5'-CTT GTG CCA CTG AAA TCA CG-3', TGF $\beta 1$, sense 5'-TGA TGT CAC CGG AGT TGT GC-3', antisense 5'-TCC AGG CTC CAA ATG TAG GG-3', Fibronectin, sense 5'-CAC TGC CCA CTC CTA CAA CC-3', antisense 5'-ATG GAT CCC AAT CCA AAT CC-3', PAI-1, sense 5'-TGA CCA CAG GAG GAG AAA CC-3', antisense 5' GGT GTT TGA TCT GGG AAG G-3'. Bovine gremlin was amplified using the primers sense 5'-CCT GAA GCG GGA CTG GTG YAA RAC-3', antisense 5'-TCG ATG GAT ATG CAA CG-3', where $Y=C+T, R=A+G$. As a control for equal amounts of RNA, either 18S rRNA or the housekeeping gene GAPDH was amplified. 18S, sense 5'-GTG GAG CGA TTT GTC TGG TT-3', antisense 5' -CGC TGA GCC AGT CAG TGT AG-3'. GAPDH, sense 5'- GGT GAT GCT GGT GCT GAG TA -3', antisense, 5'- GTC TTC TGG GTG GAG TGA T -3 '.

To confirm the correct PCR product was amplified PCR products were subcloned into the vector pCRII-TOPO (Invitrogen). Subcloned cDNAs were isolated by colony PCR amplification. Sequencing was performed using an automated ABI 3310 DNA sequencing system. Sequence reactions were carried out with the ABI prism big dye terminator cycle sequencing ready reaction kit (Perkin-Elmer). The sequences obtained were compared against GenBank and expressed sequence tag (EST) databases using BLAST searches. ${ }^{27}$

\section{Animal model and immunohistochemistry}

The animal model is as described by Cox et al..$^{28}$ Briefly, male c57Bl/6 mice (20-25 g at 5-6 weeks old) were randomly assigned to non-diabetic control or diabetic groups. Diabetes was induced by a single intraperitoneal injection of streptozotocin (Sigma) at $180 \mathrm{mg} / \mathrm{kg}$ bodyweight. Control animals received an equivalent dose of the drug vehicle (citrate buffer at $\mathrm{pH}$ 4.6). The mice were caged individually and allowed food and water ad libitum. Blood glucose levels were measured
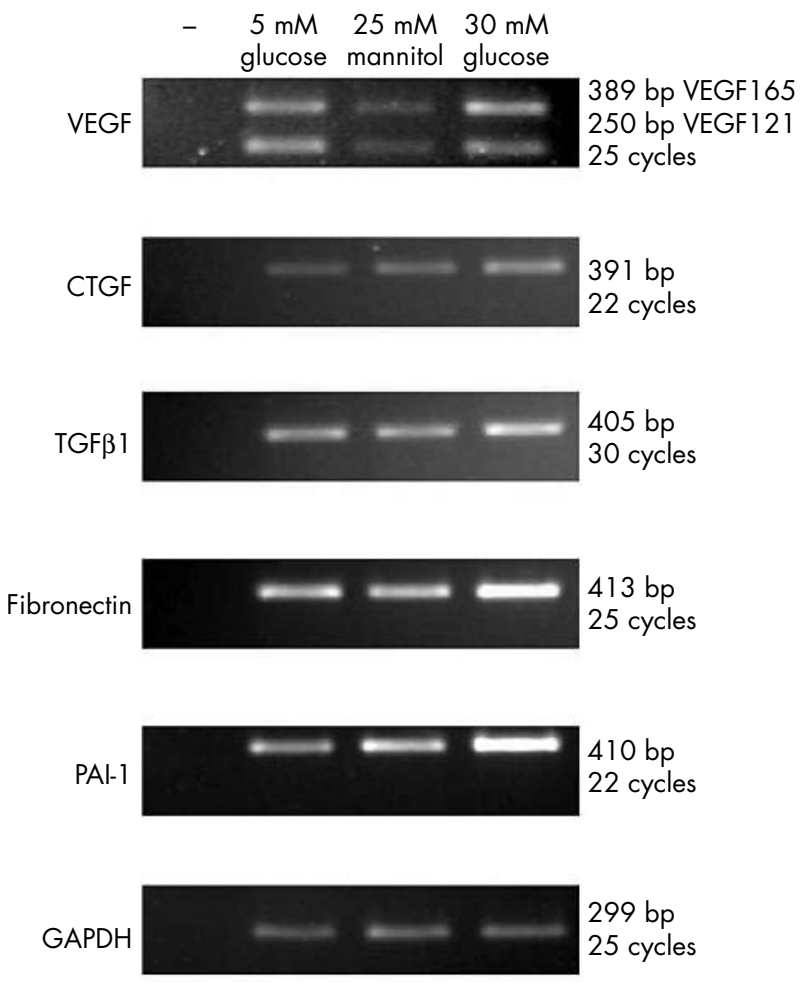

Figure 1 Glucose regulated gene expression in BRPC. RT-PCR analyses of quantitatively standardised total RNA samples from BRPC cultured in $5 \mathrm{mM}$ glucose, $5 \mathrm{mM}$ glucose, and $25 \mathrm{mM}$ mannitol (as an osmolarity control), or $30 \mathrm{mM}$ glucose for 7 days. SDW was used as a negative control instead of cDNA and is indicated by -. 18S ribosomal RNA was used as a control for equal input amounts of RNA.

fortnightly. Diabetic animals with blood glucose levels between $20 \mathrm{mM}$ and $30 \mathrm{mM}$ were included in the study. Groups of 8-10 animals were taken for each experimental and control group and the experiment was carried out three times. All animals were sacrificed after 8 weeks' duration of diabetes.

An anti-gremlin antibody was generated by Fusion Antibodies (Belfast). Sections of mouse eyes were de-waxed and rehydrated in PBS. The sections were then subjected to antigen retrieval for 20 minutes in citrate buffer $(\mathrm{pH}$ 6.0) in a pressure cooker. After washing in PBS, the sections were blocked with 5\% normal goat serum, 1\% BSA, $0.01 \%$ Triton$\mathrm{X} 100$ and then incubated in primary antibody to gremlin at 1:100 dilution overnight at $4^{\circ} \mathrm{C}$. Controls were perfomed using primary antibody exclusion and rabbit non-immune serum. Before detection using the anti-rabbit Envision+System (Dako Ltd.), endogenous peroxidase activity was quenched in 3\% hydrogen peroxide. After allowing diaminobenzidine reaction product to develop, the sections were then washed extensively, counterstained with haematoxylin, and mounted with Glycermount (Dako Ltd).

\section{RESULTS \\ Glucose induced growth factor gene expression in BRPC}

The expression of growth factor genes suggested to be involved in the pathogenesis of diabetic retinopathy, such as VEGF, TGF $\beta$, and $\mathrm{CTGF}^{29-31}$ were examined. Figure 1 shows the results of RT-PCR for glucose induced gene expression in BRPC. All three growth factor genes examined, VEGF, CTGF, and TGF $\beta 1$ were expressed. Two alternatively spliced forms of bovine VEGF were expressed; VEGF 164 (orthologue of human VEGF 165) and VEGF 120 (orthologue of human 


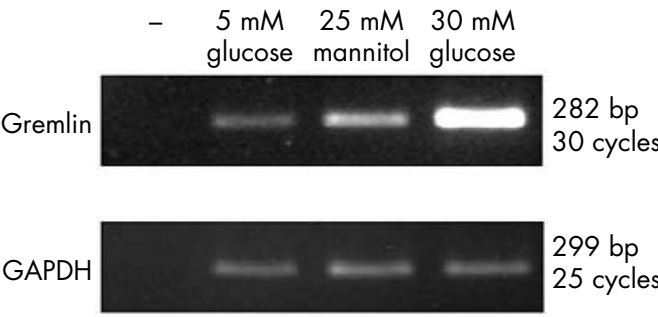

B

Human: 326 cctgaagcgagactggtgcaaaacccagccgcttaagcagaccatecacgaggaaggctg 385 Bovine: 1 ectgaagegggactggtgtaaaacecagecgetgaageagacegtecacgaggagggetg 60

Human: 386 caacagtegcaccatcateaaccgettetgttacggecagtgcaactctttetacatcce 445 Bovine: 61 caacagcegtaccatcatcaacegettetgctacggccagtgcasctcettetacatcec 120

Human: 446 caggeacatecggaaggaggaaggttectttcagtectgetecttetgeaagcecaagaa 505 Bovine: 121 caggcacatccggaaagaggagggetcetttcagtcctgetccttttgcaagcceaagaa 180

Human: 506 attcactaccatgatggteacacteaactgecetgaactacagecacetaceagaagaa 565 Bovine: 181 attcaccaccatgatggtcactctcaactgtcctgaactccagccaccaccasagaga 240

Human: 566 gagagtcacacgtgtgaagcagtgtcgttgcatatccatcga 607

Bovine: 241 ||| ||||| ||||| ||||||||| ||||||||||||||||||

Score -416 bits (216), Expect = e-113

Identities $=260 / 282(92 \mathrm{~s})$

strand $=$ plus $/$ plus

Figure 2 Gremlin is upregulated by glucose in BRPC. (A) RT-PCR analyses of quantitatively standardised total RNA samples from BRPC cultured in $5 \mathrm{mM}$ glucose, $5 \mathrm{mM}$ glucose, and $25 \mathrm{mM}$ mannitol (as an osmolarity control), or $30 \mathrm{mM}$ glucose for 7 days. SDW was used as a negative control instead of cDNA and is indicated by -. 18S ribosomal RNA was used as a control for equal input amounts of RNA. (B) The bovine Gremlin PCR product was subcloned in to the vector pCR2. 1TOPO (Invitrogen) and sequenced in both directions. The sequence was aligned in a pairwise alignment using "BLAST 2 sequences" ${ }^{\prime 34}$ with its human homologue (accession number AF110137).

VEGF 121). Expression levels of all three growth factor genes increased under conditions of elevated glucose. Basement membrane thickening and increased contractility and coagulation are associated with diabetic retinopathy. ${ }^{52} 33$ The expression of genes associated with these processes was also examined by RT-PCR. Expression of both fibronectin and PAI-1 increased (fig 1).

\section{Gremlin expression in BRPC}

Figure 2A shows increased expression of gremlin in BRPC exposed to $30 \mathrm{mM}$ glucose for 7 days. The gremlin PCR product obtained was subcloned and sequenced. The sequence of bovine gremlin was determined. Following pairwise using "BLAST 2 sequences" ${ }^{\prime 34}$ with its human homologue (accession number AF110137) the sequence showed $92 \%$ identity to its human homologue, over the amplified region (fig 2B). This sequence of bovine Gremlin was translated and aligned with a translation of the human mRNA sequence. At the protein level the homology is $98 \%$ identity, data not shown. Western blotting for gremlin (data not shown) demonstrates that gremlin is both cell associated and secreted.

\section{Regulation of bovine gremlin expression}

Regulation of gremlin expression was examined. BRPCs were cultured in $30 \mathrm{mM}$ glucose plus inhibitors of signalling pathways. Inhibition of the MEK signalling pathway by PD 98059, uncoupling of oxidative phosphorylation by CCCP, or TGF $\beta$ signalling, using $\alpha$ TGF $\beta 1$ antibody all modulate gremlin expression. Inhibition of protein kinase $\mathrm{C}$ signalling
A
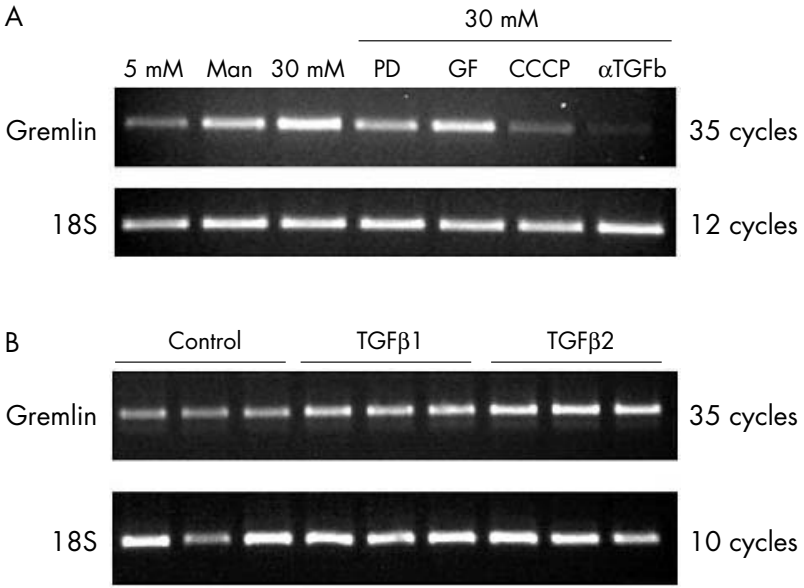

Figure 3 Regulation of bovine gremlin expression. (A) RT-PCR analyses of quantitatively standardised total RNA samples from BRPC cultured in $5 \mathrm{mM}$ glucose, $5 \mathrm{mM}$ glucose and $25 \mathrm{mM}$ mannitol (as an osmolarity control), $30 \mathrm{mM}$ glucose or $30 \mathrm{mM}$ glucose plus $10 \mu \mathrm{M}$ PD 98059, or $10 \mu \mathrm{M}$ GF $109203 \mathrm{X}$, or $500 \mathrm{nM}$ CCCP, or $1 \mu \mathrm{g} / \mathrm{ml} \alpha \mathrm{TGF} \beta 1$ antibody for 7 days. 18S ribosomal RNA was used as a control for equal input amounts of RNA. (B) RT-PCR analyses of quantitatively standardised total RNA samples from BRPC cultured in $5 \mathrm{mM}$ glucose (control), $5 \mathrm{mM}$ glucose and $10 \mathrm{ng} / \mathrm{ml} \mathrm{TGF} \beta 1$, and $5 \mathrm{mM}$ glucose and $10 \mathrm{ng} / \mathrm{ml}$ TGF $\beta 2$. 18S ribosomal RNA was used as a control for equal input amounts of RNA.

by GF109203X had no effect on gremlin expression. Gremlin expression was measured by RT-PCR (fig 3A). Culturing BRPC in $30 \mathrm{mM}$ glucose and $\alpha \mathrm{TGF} \beta 1$ antibody abolishes gremlin expression. Culturing BRPC in $30 \mathrm{mM}$ glucose and PD 98059 or CCCP reduces gremlin expression, therefore implying the MAPK pathway and hyperglycaemia induced ROS in regulation of gremlin expression in this model. To determine if gremlin was directly regulated by TGF $\beta$ in BRPC, the cells were cultured in $5 \mathrm{mM}$ glucose and $10 \mathrm{ng} / \mathrm{ml} \mathrm{TGF} \beta 1$ or $10 \mathrm{ng} / \mathrm{ml}$ TGF $\beta 2$. Again gremlin expression was examined by RT-PCR and was found to increase with both TGF $\beta 1$ and TGF 32 stimulation (fig 3B).

\section{Gremlin is expressed in the retina of diabetic mice}

Gremlin immunoreactivity was localised to the nerve fibre layer, ganglion cell layer and inner plexiform layers in the retina of both non-diabetic (fig 4A), and diabetic mice (fig 4B). The diabetic animals also demonstrate gremlin immunoreactivity in the outer retina (fig 4B), and also at the level of the vascular wall (arrow)-especially noticeable in the large retinal vessels (fig 4C).

\section{DISCUSSION}

Within the retina, pericytes provide vascular stability, exert control over endothelial cell proliferation and morphology, and microvessel architecture. ${ }^{14}$

Multiple growth factors are involved in the regulation of the retinal vasulature, and are also involved in the pathogenesis of diabetic retinopathy. We have demonstrated in this study the increased expression of the profibrotic growth factors, CTGF and TGF $\beta 1$, and the angiogenic factor VEGF in retinal pericytes exposed to high concentrations (30 mM) of extracellular glucose. CTGF is a novel, cysteine rich secreted protein, which is implicated in fibrotic disorders and has been associated with proliferative retinopathies. ${ }^{35} 36$ More recently, other studies show increased expression of CTGF in the diabetic retina ${ }^{37}$ and demonstrate the expression of CTGF in pericytes and point to a role for CTGF in diabetic retinopathy. ${ }^{38}$ High glucose induced CTGF expression has 

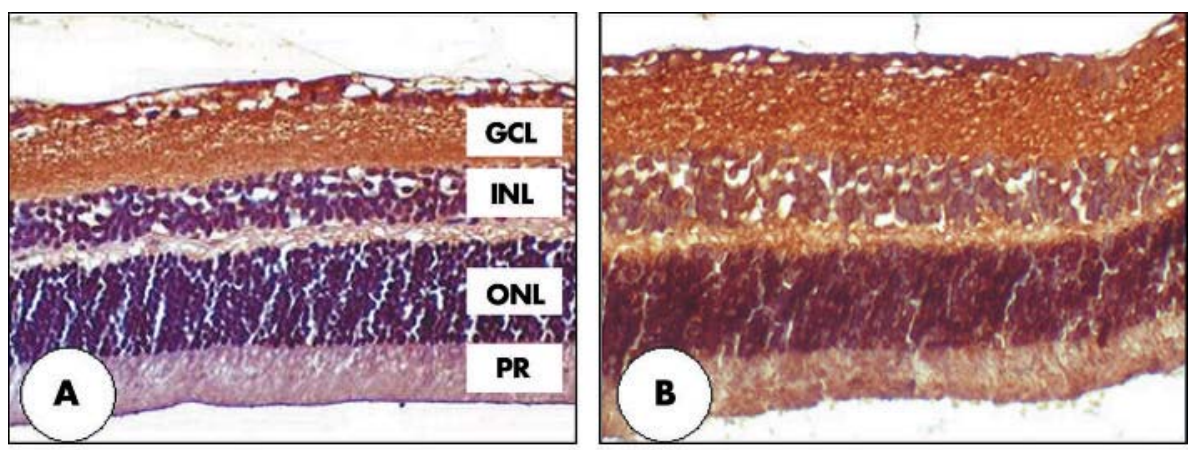

Figure 4 Immunohistochemistry of gremlin in retina of diabetic and nondiabetic mice. The nerve fibre layer (NFL), ganglion cell layer (GCL), and inner plexiform layers (IPL) of both nondiabetic (A) and diabetic (B) mice show strong immunoreactivity. Diabetic animals demonstrate gremlin immunoreactivity in the outer retina (B) and also at the level of the vascular endothelium (arrow), especially noticeable in the large retinal vessels (C). Primary antibody omission controls show no apparent deposition of DAB reaction product (D). Original
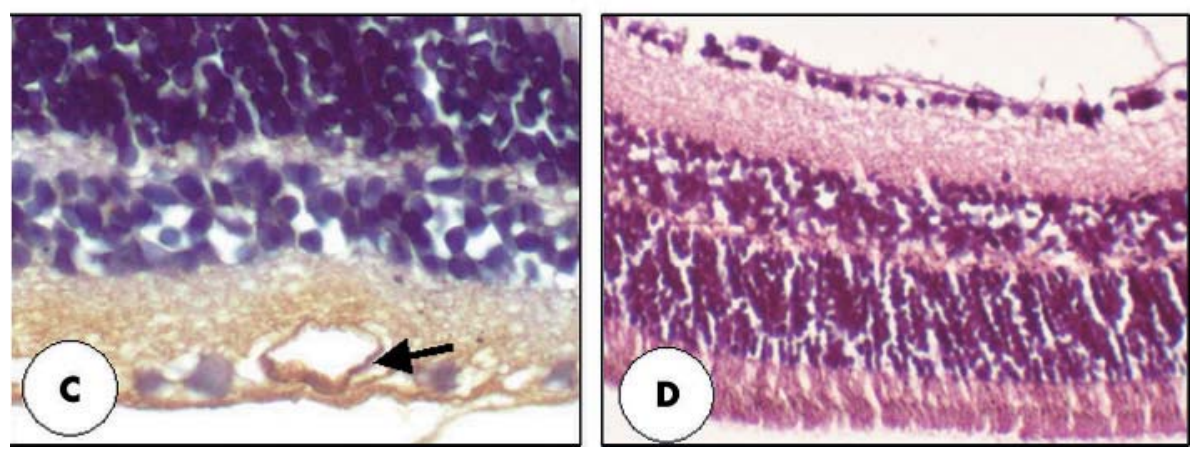
magnifications: $\times 200(A, B$, and D). $\times 400$ (C). The outer nuclear layer (ONL) and photoreceptors (PR) are also labelled.

been demonstrated in other cell types such as mesangial cells, ${ }^{22}$ where it may contribute to increased fibrosis by inhibiting matrix breakdown ${ }^{39}$ and mediating TGF $\beta$ induced matrix deposition. ${ }^{40}$ TGF $\beta 1$, is a member of a superfamily of multifunctional cytokines, which regulate multiple cellular functions including growth, differentiation, and death. TGF $\beta 1$ is a potent inducer of extracellular matrix proteins and inhibits matrix degradation. ${ }^{41}$ TGF $\beta$ produced in cocultures of endothelial cells and pericytes has been demonstrated to inhibit retinal endothelial cell proliferation. ${ }^{42}$ We have demonstrated here increased TGF $\beta$ transcription in pericytes in response to elevated glucose. VEGF, a potent angiogenic factor, is synthesised by pericytes and is capable of stimulating endothelial cells to proliferate, and may synergistically act with other growth factors to enhance this effect. ${ }^{43}$ VEGF has been demonstrated to increase CTGF levels in retinal capillary cells mediated primarily by PI3-kinase activation. ${ }^{31}$ In retinal pigmented epithelial cells, $30 \mathrm{mM}$ glucose also induces VEGF expression. ${ }^{44}$ We have demonstrated in this study direct induction by high glucose of these growth factors, VEGF, CTGF and TGF $\beta$, thus demonstrating that concomitant overexpression of growth factors by retinal pericytes occurs in response to elevated glucose levels and may contribute to the pathogenesis of diabetic retinopathy.

Hyperglycaemia induces basement membrane thickening in the diabetic retina and this may contribute to the closure of capillaries. ${ }^{8}$ Increased coagulation and contractility are also associated with diabetic retinopathy. We have demonstrated here that when exposed to elevated levels of glucose, retinal pericytes increase fibronectin and PAI-1 expression. Increased CTGF levels may also contribute to increased matrix deposition..$^{39}{ }^{40}$ Pericytes may also contribute to the process of basement membrane thickening by secreting fibronectin. Fibronectin mRNA elevation has previously been demonstrated in pericytes in response to $22 \mathrm{mM}$ glucose, ${ }^{9}$ and we demonstrate increases following exposure of pericytes to $30 \mathrm{mM}$ glucose.

There exists an emerging paradigm that patterns of developmental gene programs reappear in the context of a disease process. ${ }^{45}$ This may attempt to repair or regenerate tissue. It is also possible that this execution of a developmental program may contribute to the disease process. One of these developmental genes is gremlin. Increased expression of gremlin has been recently demonstrated in models of fibrotic disease processes, most notably diabetic nephropathy. ${ }^{22}$ We have also demonstrated in this study that increased gremlin expression is associated with retinal pericytes exposed to high extracellular glucose. We have shown that gremlin expression in retinal pericytes can be abolished by culturing pericytes with $\alpha \mathrm{TGF} \beta 1$ antibody, and induced by stimulation with either TGF $\beta 1$ or TGF $\beta 2$, therefore implying this signalling pathway in gremlin expression.

Gremlin gene expression is induced in response to high glucose in this system. Its expression is modulated by the MAPK, ROS, and TGF $\beta$ pathways, all of which are reported to have a role in the pathogenesis of diabetic retinopathy (reviewed by Brownlee ${ }^{46}$ ). The concomitant increased expression of multiple profibrotic genes and gremlin in retinal pericytes exposed to $30 \mathrm{mM}$ glucose, and regulation of gremlin expression by the profibrotic cytokine, TGF $\beta$ may imply a role for gremlin in fibrogenesis. Gremlin is a 184 amino acid protein and a member of the cysteine knot superfamily. The protein is highly conserved during evolution and is present in soluble and cell associated forms. It belongs to a novel family of bone morphogenetic protein (BMP) antagonists that includes the head inducing factor Cerberus and the tumour suppressor DAN. These proteins have important roles in limb development and neural crest cell differentiation. Gremlin expression can be induced in mesangial cells in response to elevated glucose, TGF- $\beta$, and cyclic mechanical strain. ${ }^{21}$ A pathogenic role may be attributed to gremlin in the context of diabetic nephropathy as overexpression of gremlin induces transdifferentiation of cultured tubular epithelial cells to a more fibroblast-like phenotype. ${ }^{47}$ We have observed in this study that gremlin protein expression in BRPC is both cell associated and secreted. As a cell associated protein it may function to alter gene expression and signalling pathways, as demonstrated by Chen et $a l^{48}$ in tumour derived cell lines. Gremlin also functions as a secreted protein and in addition we have shown in this study that gremlin is expressed in the retinas of both non-diabetic and diabetic mice, and that expression 
increases in the outer retina and the vascular wall of diabetic animals. Mathura et $a l^{49}$ demonstrated high expression of BMPs in the adult outer retina, more specifically the RPE, and suggest that both BMP-2 and BMP-4 may serve as negative growth regulators in the retina. The expression of gremlin in the vascular endothelium is significant as this may contribute to proliferation of the vascular endothelium. Trousse et a $l^{50}$ demonstrate how BMP-4 mediates apoptosis in the retina, and this may be antagonised by Noggin, another member of the BMP antagonist family. As gremlin is a known antagonist of BMPs, it may have a role in proliferation by antagonising the antiproliferative effects of BMP in the retina. Therefore, modulation of BMP expression may have a role in proliferative retinopathies.

\section{ACKNOWLEDGEMENTS}

The authors gratefully acknowledge funding from the Programme for Research in Third Level Institutes (PRTLI), Ireland.

\section{Authors' affiliations}

R Kane, C Godson, School of Medicine and Medical Science University, College Dublin, Republic of Ireland

C O'Brien, Department of Ophthalmology, Mater Misericordiae

Hospital, Dublin, Republic of Ireland

R Kane, C Godson, C O'Brien, Conway Institute for Biomolecular and Biomedical Research, University College Dublin and the Dublin Molecular Medicine Centre, Republic of Ireland

L Stevenson, A W Stitt, Ophthalmology and Vision Science, Queen's University Belfast, Institute of Clinical Science, Royal Victoria Hospital, Belfast, UK

\section{REFERENCES}

1 American Diabetes Association. Diabetic retinopathy. Clin Diabetes 2001;19:29-32.

2 The Diabetes Control and Complications Trial Research Group. The effect of intensive treatment of diabetes on the development and progression of longterm complications in insulin-dependent diabetes mellitus. N Engl J Med 1993;329:977-86.

3 UK Prospective Diabetes Study (UKPDS) Group. Intensive blood-glucose control with sulphonylureas or insulin compared with conventional treatment and risk of complications in patients with type 2 diabetes (UKPDS 3). Lancet 1998;352:837-53.

4 Yoshii H, Uchino H, Ohmura C, et al. Clinical usefulness of measuring urinary polyol excretion by gas-chromatography/mass-spectrometry in type 2 diabetes to assess polyol pathway activity. Diabetes Research and Clinical Practice 2001;51:115-23.

5 Ishii H, Koya D, King GL. Protein kinase C activation and its role in the development of vascular complications in diabetes mellitus. J Mol Med 1997;76:21-31

6 Chakrabarti S, Cukiernik M, Hileeto D, et al. Role of vasoactive factors in the pathogenesis of early changes in diabetic retinopathy. Diabetes/Metabolism Research and Reviews 2000; 16:393-407.

7 Gurler B, Vural H, Yilmaz N, et al. The role of oxidative stress in diabetic retinopathy. Eye 2000;14:730-5.

8 Cai J, Boulton $M$. The pathogenesis of diabetic retinopathy: old concepts and new questions. Eye 2002;16:242-60.

9 Aiello L, Robinson G, Lin Y, et al. Identification of multiple genes in bovine retinal pericytes altered by exposure to elevated levels of glucose by using mRNA differential display. PNAS 1994;91:6231-5.

10 Diaz-Flores L, Gutierrez R, Varela H, et al. Microvascular pericytes: a review of their morphological and functional characteristics. Histol Histopathol $1991 ; 6: 269-86$.

11 Herman I, D'Amore PA. Microvascular pericytes contain muscle and nonmuscle actins. J Cell Biol 1985;101:43-52.

12 Orlidge A, D'Amore PA. Inhibition of capillary endothelial cell growth by pericytes and smooth muscle cells. J Cell Biol 1987; 105:1455-62.

13 Canfield A, Allen T, Grant $M$, et al. Modulation of extracellular matrix biosynthesis by bovine retinal pericytes in vitro: effects of the substratum and cell density. J Cell Sci 1990;96:159-69.

14 Hellstrom M, Gerhardt H, Kalen M, et al. Lack of pericytes leads to endothelial hyperplasia and abnormal vascular morphogenesis. J Cell Biol $2001 ; 153: 543-54$.

15 Cogan D, Toussaint D, Kuwabara T. Retinal vascular pattern. IV. Diabetic retinopathy. Arch Ophthalmol 1961;66:366-78.

16 Hsu DR, Economides AN, Wang X, et al. The Xenopus dorsalizing factor gremlin identifies a novel family of secreted proteins that antagonize BMP activities. Mol Cell 1998;1:673-83.

17 Isaacs N. Cystine knots. Curr Opin Struct Biol 1995:5:391-5.

18 Topol L, Marx M, Laugier D, et al. Identification of drm, a novel gene whose expression is suppressed in transformed cells and which can inhibit growth of normal but not transformed cells in culture. Mol Cell Biol 1997;17:4801-10.
19 Merino R, Rodriguez-Leon J, Macias D, et al. The BMP antagonist Gremlin regulates outgrowth, chondrogenesis and programmed cell death in the developing limb. Development 1999;126:5515-22.

20 Zuniga A, Haramis A-PG, McMahon AP, et al. Signal relay by BMP antagonism controls the SHH/FGF4 feedback loop in vertebrate limb buds. Nature 1999;401:598-602.

21 McMahon R, Murphy M, Clarkson M, et al. IHG-2, a mesangial cell gene induced by high glucose, is human gremlin. Regulation by extracellular glucose concentration, cyclic mechanical strain, and transforming growth factor-beta 1. J Biol Chem 2000;275:9901-4.

22 Murphy M, Godson C, Cannon S, et al. Suppression subtractive hybridization identifies high glucose levels as a stimulus for expression of connective tissue growth factor and other genes in human mesangial cells. J Biol Chem 1999; 274:5830-4.

23 Dudley D, Pang L, Decker S, et al. A synthetic inhibitor of the mitogenactivated protein kinase cascade. PNAS 1995;92:7686-9.

24 Toullec D, Pianetti P, Coste H, et al. The bisindolylmaleimide GF 109203X is a potent and selective inhibitor of protein kinase C. J Biol Chem 1991;266:15771-81

25 Nishikawa T, Edelstein D, Du XL, et al. Normalizing mitochondrial superoxide production blocks three pathways of hyperglycaemic damage. Nature 2000;404:787-90.

26 Tsang ML-S, Zhou L, Zheng B-L, et al. Characterization of recombinant soluble human transforming growth factor-[beta] receptor Type II (rhTGF-[beta]sRII). Cytokine 1995;7:389-97.

27 Altschul SF, Gish W, Miller W, et al. Basic local alignment search tool. J Mol Biol 1990;215:403-10.

28 Cox O, Simpson DAC, Stitt AW, et al. Sources of PDGF expression in murine retina and the effect of short-term diabetes. Mol Vis 2003;9:665-72.

29 Lu M, Adamis AP. Vascular endothelial growth factor gene regulation and action in diabetic retinopathy. Ophthalmol Clin N Am 2002;15:69-79.

30 Spirin K, Saghizadeh M, Lewin S, et al. Basement membrane and growth factor gene expression in normal and diabetic human retinas. Curr Eye Res 1999; 18:490-9.

31 Suzuma K, Naruse K, Suzuma I, et al. Vascular endothelial growth factor induces expression of connective tissue growth factor via KDR, Flt1, and phosphatidylinositol 3-kinase-akt-dependent pathways in retinal vascular cells. J Biol Chem 2000;275:40725-31.

32 Cagliero $E$, Maiello $M$, Boeri $D$, et al. Increased expression of basement membrane components in human endothelial cells cultured in high glucose. J Clin Invest 1988;82:735-8.

33 Grant MB, Spoerri PE, Player DW, et al. Plasminogen activator inhibitor (PAI)1 overexpression in retinal microvessels of PAl-1 transgenic mice. Invest Ophthalmol Vis Sci 2000:41:2296-302.

34 Tatusova TA, Madden TL. BLAST 2 S, a new tool for comparing protein and nucleotide sequences. FEMS Microbiol Lett 1999;174:247-50.

35 Hinton D, He S, Jin M, et al. Novel growth factors involved in the pathogenesis of proliferative vitreoretinopathy. Eye 2002;16:422-8.

36 Wunderlich K, Senn B, Todesco L, et al. Regulation of connective tissue growth factor gene expression in retinal vascular endothelial cells by angiogenic growth factors. Graefes Arch Clin Exp Ophthalmol 2000;238:910-15.

37 Tikellis C, Cooper ME, Twigg SM, et al. Connective tissue growth factor is upregulated in the diabetic retina: amelioration by angiotensin-converting enzyme inhibition. Endocrinology 2004; 145:860-6.

38 Kuiper EJ, Witmer AN, Klaassen I, et al. Differential expression of connective tissue growth factor in microglia and pericytes in the human diabetic retina. Br J Ophthalmol 2004:88:1082-7.

39 McLennan SV, Wang XY, Moreno V, et al. Connective tissue growth factor mediates high glucose effects on matrix degradation through tissue inhibitor of matrix metalloproteinase type 1: implications for diabetic nephropathy. Endocrinology 2004; 145:5646-55.

40 Weston BS, Wahab NA, Mason RM. CTGF mediates TGF- $\beta$-induced fibronectin matrix deposition by upregulating active $\alpha 5 \beta 1$ integrin in human mesangial cells. J Am Soc Nephrol 2003;14:601-10.

41 Choi M. Mechanism of transforming growth factor-betal signaling. Kidney Int Suppl 2000;77:S53-8

42 Antonelli-Orlidge A, Saunders KB, Smith SR, et al. An activated form of transforming growth factor beta is produced by cocultures of endothelial cells and pericytes. Proc Natl Acad Sci USA 1989;86:4544-8.

43 Castellon R, Hamdi HK, Sacerio I, et al. Effects of angiogenic growth factor combinations on retinal endothelial cells. Exp Eye Res 2002;74:523-35.

44 Young TA, Wang H, Munk S, et al. Vascular endothelial growth factor expression and secretion by retinal pigment epithelial cells in high glucose and hypoxia is protein kinase C-dependent. Exp Eye Res 2005;80:651-62.

45 Lappin DWP, McMahon R, Murphy M, et al. Gremlin: an example of the reemergence of developmental programmes in diabetic nephropathy. Nephrol Dial Transplant 2002;17:65-7.

46 Brownlee M. Biochemistry and molecular cell biology of diabetic complications. Nature 2001;4414:813-20.

47 Murphy M, McMahon R, Clarkson Mea. Induction of gremlin expression in the remnant kidney in vivo and during TGF-induced epithelial mesenchymal transformation in vitro. J Am Soc Nephrol 2000;1 1:625A.

48 Chen B, Athanasiou M, Gu Q, et al. Drm/Gremlin transcriptionally activates p21Cipl via a novel mechanism and inhibits neoplastic transformation. Biochem Biophys Res Commun 2002;295:1135-41.

49 Mathura JR Jr, Jafari N, Chang JT, et al. Bone morphogenetic proteins-2 and -4: negative growth regulators in adult retinal pigmented epithelium. Invest Ophthalmol Vis Sci 2000:41:592-600.

50 Trousse F, Esteve P, Bovolenta P. BMP4 mediates apoptotic cell death in the developing chick eye. J Neurosci 2001;21:1292-301. 